\title{
Poor oral health including active caries in 187 UK professional male football players: Clinical dental examination performed by dentists.
}

Ian Needleman ${ }^{1}$, Paul Ashley², Lyndon Meehan ${ }^{3}$, Aviva Petrie ${ }^{4}$, Richard Weiler ${ }^{5,6,7}$, Steve McNally ${ }^{8}$, Chris Ayer ${ }^{9}$, Rob Hanna ${ }^{10}$, Ian Hunt ${ }^{11}$, Steven Kell ${ }^{12}$, Paul Ridgewell ${ }^{13}$, Russell Taylor $^{14}$

1. Unit of Periodontology and International Centre for Evidence-Based Oral Health, UCL Eastman Dental Institute, London, UK

2. Unit of Paediatric Dentistry, UCL Eastman Dental Institute, London, UK

3. Cardiff City FC Dental Practitioner, Parade House Dental Centre, Cardiff, UK

4. Unit of Biostatistics, UCL Eastman Dental Institute, London, UK

5. West Ham United Football Club, Sports Medicine \& Sports Science Department, West Ham United FC Training Ground, Chadwell Heath, Essex, UK

6. University College London Hospitals NHS Foundation Trust \& UCLH Institute of Sport, Exercise and Health, London, UK

7. The FA Centre for Disability Football Research, Burton-Upon-Trent, England

8. Football Medicine \& Science Department, Manchester United Football Club, Manchester, UK

9. Hull City Tigers Dental Practitioner, Ayer Surgery, Hull, UK

10. Southampton FC Dental Practitioner, Southampton, UK

11. Manchester United FC Dental Practitioner, Maple Dental Care, Manchester, UK

12. Brighton and Hove Albion FC Dental Practitioner, Lewes High Street Dental Practice, Lewes, UK

13. Swansea City AFC Dental Practitioner, Swansea, UK

14. Sheffield United FC Dental Practitioner, Sheffield, UK

Corresponding author

Prof. Ian Needleman

Unit of Periodontology, UCL: Eastman Dental Institute, 256 Gray's Inn Road, London WC1X 8LD, UK $+44(0) 2034562340$

i.needleman@ucl.ac.uk

Word count: 2,999 
Key words: Oral health, Football, Sports Medicine, Athletic Performance, Primary Prevention

\section{ABSTRACT}

\section{Background/Aim}

The few studies that have assessed oral health in professional/elite football suggest poor oral health with minimal data on impact on performance. The aim of this research was to determine oral health in a representative sample of professional footballers in the UK and investigate possible determinants of oral health and self-reported impact on wellbeing, training and performance.

\section{Methods}

Clinical oral health examination of senior squad players using standard methods and outcomes carried out at club training facilities. Questionnaire data were also collected. Eight teams were included, five Premier League, two Championship and one League One.

\section{Results}

Six dentists examined 187 players who represented $>90 \%$ of each senior squad. Oral health was poor: $37 \%$ players had active dental caries, $53 \%$ dental erosion and $5 \%$ moderate-severe irreversible periodontal disease. $45 \%$ were bothered by their oral health, $20 \%$ reported an impact on their quality of life and $7 \%$ on training or performance. Despite attendance for dental check-ups, oral health deteriorated with age.

\section{Conclusions}

This is the first large, representative sample study in professional football. Oral health of professional footballers is poor and this impacts on wellbeing and performance. Successful strategies to promote oral health within professional football are urgently needed and research should investigate models based on best evidence for behaviour change and implementation science. Furthermore, this study provides strong evidence to support oral health screening within professional football. 


\section{What are the new findings?}

- First large representative sample study of oral health in professional football found that oral health was poor

- $\quad 37 \%$ of players had active dental caries, $53 \%$ dental erosion and $5 \%$ moderate-severe irreversible periodontal disease

- $45 \%$ were bothered by their oral health, $20 \%$ reported an impact on their quality of life and $7 \%$ on training or performance

\section{How might it impact on clinical practice in the near future?}

Oral diseases are preventable with cost-effective interventions. Oral health screening and oral health promotion should both become routine elements of medical care in professional football. 


\section{Introduction}

There is accumulating evidence that oral health of elite or professional athletes is poor with common self-reported impacts on wellbeing, training and performance ${ }^{1 ; 2}$. We have reported high levels of preventable conditions including dental caries, dental erosion, and periodontal diseases in a study of 300 athletes at the London 2012 Olympic Games ${ }^{1}$ with $30 \%$ of participants reporting an impact of oral health on their quality of life and almost $20 \%$ on their training or performance. More recently, a systematic review of professional and elite sport from our group has shown similar findings across a wide range of sports ${ }^{2}$. These findings have led to the development of position/consensus statements with recommendations to promote oral health and related research as part of sport and exercise medicine $\mathrm{e}^{3 ; 4}$.

Oral health is a determinant of life quality ${ }^{5}$ and there is a wealth of literature demonstrating impacts of poor oral health on quality of life including caries ${ }^{6}$, periodontal disease ${ }^{7}$ and pericoronitis ${ }^{8}$. Exploratory analyses from London 2012 suggested that caries was associated with negative impacts on life quality and self-reported performance ${ }^{1}$. Other than symptomatic effects, psycho-social impacts of poor oral health are recognised as a major influence on quality of life ${ }^{5}$. Therefore, if oral health is poor in professional football, it would be reasonable to expect an impact on quality of life and potentially performance.

Our systematic review found only three studies of oral health in professional football ${ }^{9-11}$. These reported poor oral health but the strength of evidence was limited by their lack of representative sampling ${ }^{11}$. Therefore, as the oral health of footballers is currently unclear and in view of the potential impact on wellbeing and performance ${ }^{12}$, the aim of this study was to evaluate the oral health of a representative sample of professional footballers and to investigate possible determinants or oral health in this group as well as the self-reported impacts on wellbeing, quality of life and performance. 


\section{METHODS}

\section{Study design}

Cross-sectional study at eight UK professional football clubs UK; Premier League: Hull FC, Manchester United FC, Southampton FC, Swansea City AFC, West Ham FC, Championship: Brighton \& Hove Albion, Cardiff FC and League One: Sheffield United FC. Informed, written consent was obtained for all participants (Research Ethics Committee, UCL Project ID Number: 5843/001). Clinical examination, recruitment, consent and administration of questionnaire was undertaken by. Eligibility criteria: member of senior team squad, able to understand the consent process, able to understand the questionnaire and age at least 18 years.

Oral health examination:

The clinical oral health examination was carried out by the normal team dentist or named dentist nominated by the club in the clubs' training or medical facilities. The examination was conducted using headtorch illumination and standard methods for oral health examination. Dental caries was measured on all teeth as enamel only or dentine following cleaning with an explorer and drying with cotton wool rolls. Erosive toothwear was recorded for all teeth using a modification of the Basic Erosive Wear Examination (BEWE) to exclude third molars ${ }^{13}$. The worst finding on anterior and posterior teeth were recorded.

Dental and orofacial trauma was recorded as; previous history of trauma and new trauma. Periodontal health was measured with the Basic Periodontal Examination, although modified to omit the ${ }^{*}$ code $^{14}$. The PUFA Index ${ }^{15}$ (Pulp, Ulceration, Fistula, Abscess) was used to measure four forms of oral sepsis and participants were asked about experience of wisdom tooth complications. All dentists involved in the study received written training on research governance issues and a teleconference was provided as requested.

Questionnaire data included demographics, health behaviours, oral symptoms and impact on wellbeing, training and performance modified from a validated health-related quality of life measure ${ }^{12}$ that we used at London $2012^{1}$.

\section{Statistical analysis}


Data were collected from questionnaires, coded appropriately and transcribed to SPSS (IBM Corp. Released 2013. IBM SPSS Statistics for Windows, Version 22.0. Armonk, NY: IBM Corp.). Counts and percentages summarised the categorical data and Chi-squared tests or Fisher's exact tests, as appropriate, were used to compare percentages in different groups. The distribution of numerical variables was assessed by examining box and whisker plots and means and standard deviations provided if the data were approximately normally distributed and medians and ranges otherwise. The non-parametric Kruskal Wallis test was used to compare the distributions of numerical variables in different groups and this was followed by post hoc comparisons when necessary. A significance level of $5 \%$ was selected for all hypothesis tests.

\section{RESULTS}

\section{Characteristics of footballers (Table 1)}

189 footballers were recruited from eight clubs with data available for 187 (two players consented but unable to participate due to time). These numbers represent a mean completeness of $96 \%$ of eligible players from each senior squad (range $89-100 \%$ ). Chief reasons for non-participation were less than 18 years of age and withholding of consent. Of the eight clubs, five were Championship, three Premier League and one League One. The median age was 24 years (range 18-39 years) and the majority of athletes were white (75.1\%) or black (14.1\%). Almost three quarters of players $(73.4 \%)$ reported attending for a check-up within the last 12 months and $21.7 \%$ reported a history of orofacial trauma due to sport. Consumption of sports drink at least three times per week was reported by $63.7 \%$ players. Ten players (5.4\%) reported current tobacco use, mostly smokeless/chewing tobacco. 
Table 1. Characteristics of footballers

\begin{tabular}{|c|c|c|}
\hline Club N = 187 & $\mathrm{n}$ & $\%$ \\
\hline A & 31 & 16.7 \\
\hline B & 15 & 8.1 \\
\hline $\mathrm{C}$ & 17 & 9.2 \\
\hline $\mathrm{D}$ & 24 & 13.0 \\
\hline $\mathrm{E}$ & 19 & 10.3 \\
\hline $\mathrm{F}$ & 22 & 11.9 \\
\hline G & 38 & 20.5 \\
\hline K & 21 & 11.4 \\
\hline Ethnicity $\mathrm{N}=185$ & $\mathbf{n}$ & $\%$ \\
\hline White & 139 & 75.1 \\
\hline Asian & 2 & 1.1 \\
\hline Black & 26 & 14.1 \\
\hline Mixed & 14 & 7.6 \\
\hline Other & 4 & 2.2 \\
\hline Tobacco use $\mathrm{N}=184$ & $\mathbf{n}$ & $\%$ \\
\hline Current & 10 & 5.4 \\
\hline Never & 174 & 94.6 \\
\hline If using tobacco: & $\mathrm{N}=184$ & \\
\hline $\mathrm{N} / \mathrm{A}$ & 173 & 94.0 \\
\hline Smoking & 1 & 0.5 \\
\hline Chewing tobacco/smokeless & 10 & 5.4 \\
\hline $\begin{array}{l}\text { Age } \mathbf{N}=187 \\
\text { Median }=24\end{array}$ & (Range 18-39) & \\
\hline Last visit to dentist $\mathrm{N}=188$ & $\mathbf{n}$ & $\%$ \\
\hline Within last 12 months & 138 & 73.4 \\
\hline$>1$ but $<2$ years ago & 30 & 16.0 \\
\hline$>2$ years ago & 20 & 10.6 \\
\hline Never & 0 & 0 \\
\hline Frequency sports drink $\mathrm{N}=168$ & $n$ & $\%$ \\
\hline Rarely or never & 5 & 3.0 \\
\hline < once a week & 7 & 4.2 \\
\hline 1-2 times a week & 49 & 29.2 \\
\hline 3-5 times a week & 68 & 40.5 \\
\hline 6 or more times a week & 39 & 23.2 \\
\hline
\end{tabular}




\section{Oral health}

Teeth present, caries and restorations (Online table 1)

Median number of teeth per athlete was 29 (range 24-32) with 36.9\% having at least one tooth affected by dental caries and $77 \%$ with one or more restorations. In footballers with one or more restorations, the mean number of teeth with restorations was five. When combining caries and restorations together (DFT), $84 \%$ of all footballers had at least one decayed or restored tooth (mean DFT $=4.6(95 \% \mathrm{Cl} 3.9,5.2)$ ). Experience of dental caries or restorations increased with age: DFT=1 or more: $77.9 \%$ of $16-24$ year olds and $92 \%$ of $25-34$ year olds. There were no statistically significant associations between last visit to dentist for dentine caries $(\mathrm{P}=0.82)$ or DFT $(\mathrm{P}=0.54)$ or for frequency of sports drink use and dentine caries $(\mathrm{P}=0.34)$ or DFT $(\mathrm{P}=0.36)$.

Dental erosion (Online table 2)

Dental erosion was present in $53.1 \%$ of footballers. In those with erosion, the severity in the most affected tooth was moderate to severe (grade $2-3$ ) in $20.9 \%$ anterior teeth and $20.6 \%$ posterior teeth. There was no statistically significant association between sports drink frequency and dental erosion (online table 3).

Periodontal health (Online tables 4 \& 5)

Gingivitis (Basic Periodontal Examination (BPE) codes 1-2), as the worst finding, was present in more than $8 / 10$ of footballers with irreversible periodontitis (BPE codes $3-4$ ) in $5 \%$ of players. In terms of extent, at least half of the mouth was affected by gingivitis in $76.7 \%$ of footballers.

Pericoronitis and oral infections

Pericoronitis (infection around wisdom teeth) affected 3.2\% footballers. $7.8 \%$ had at least one PUFA finding (open pulp, ulceration, fistula, abscess).

Self-reported oral conditions 
The proportion of players reporting oral conditions were: current problems or pain in the mouth: $15.6 \%$, pain related to teeth: $10.2 \%$, current sensitivity to hot or cold from the mouth: $27.4 \%$, previous history of swelling/infection around wisdom teeth $14.1 \%$.

Impact of oral health on performance (Online table 6)

There was a substantial self-reported negative impact of oral health on wellbeing and performance. More than $45 \%$ of footballers were bothered by their oral health with $19.6 \%$ reporting an impact on their quality of life and $6.9 \%$ reporting an impact on training or performance.

Effect of team on caries (Online tables $7 \&$ 8)

Caries experience varied markedly by club: (range $5.3 \%-52.4 \%, p=0.014$ ). Periodontal health was also statistically significantly different between teams.

Exploration of determinants of quality of life and performance (online table 9)

Dentine caries had a highly statistically significant association with athlete-reported impacts ('bothered' by oral health, impact of oral health on quality of life or training and performance) analysed by median number of carious lesions per athlete ( $P=0.007)$. A statistically significant association was also found for DFT $(p=0.037)$. Several self-reported oral symptoms also had a statistically significant association with athlete-reported impacts: current pain in mouth $(P=0.002)$, pain related to teeth $(p=0.010)$, tooth sensitivity to hot/cold $(P=0.003)$ and history of wisdom tooth swelling/infections $(P=0.023)$

\section{DISCUSSION}

This survey shows high levels of poor oral health with associated impacts among professional footballers. Almost 4/10 players had untreated dental caries. Experience of dental caries or restorations increased with age: DFT (decayed \& filled teeth) $\geq 1: 77.9 \%$ of 16-24 year olds and $92 \%$ of $25-34$ year olds. Dental erosion was present in more than half of footballers. Inflammatory gingivitis was seen in over $80 \%$ of individuals and irreversible periodontitis in $5 \%$. Sixteen percent of players reported current problems or pain in their 
mouths. Self-reported impacts were frequent with $45 \%$ players being 'bothered' by their oral health and almost $20 \%$ reporting it affected their quality of life: $7 \%$ reported an impact on training or performance. Self-reported impacts were statistically significantly associated with dental caries, current pain in the mouth, history of wisdom tooth swelling/infections and tooth sensitivity.

\section{Comparison with previous studies}

Our recent systematic review ${ }^{2}$ identified three studies conducted in professional or elite football (an updated search on 13/2/2015 did not identify additional data). The sample sizes of the studies were small ( $n=18-34)$ and unlikely to be representative. Although only limited data were reported, the oral health in these studies was also poor. Compared to the mean DFT of 4.6 in this study, the mean DFT values were $5.1^{11}, 7.15^{10}$ and $21 \%$ players with untreated caries ${ }^{9}$. No data were presented for erosion. Periodontal inflammation was prevalent in one study with $60 \%$ of the players reporting gum bleeding ${ }^{11}$. Although no study reported impact of oral health on performance, one study found a statistically significant correlation between periodontal health and muscle injuries ${ }^{11}$. Therefore, overall, the findings from the UK are consistent with other countries.

\section{Comparison with UK population data}

Studies investigating oral health and elite sport to date have suffered from a lack of comparative or control data ${ }^{2}$. We did not recruit a control population for this study, however some insights into dental caries levels can be gained through comparison with data from the Adult Dental Health Survey for England, Wales and Northern Ireland (2009) ${ }^{16}$. In general footballers seem to have more restorations and similar or higher levels of untreated dentine caries. The proportion of footballers with dentine caries was higher in the 16-24 age group (38.3\%) than the comparable group from the ADHS (30\%). $69.8 \%$ of $16-24$ year old footballers and $88.3 \%$ of $25-34$ year olds had one or more restorations. Comparable figures from the ADHS were $53 \%$ and $75 \%$. The mean number of teeth with restorations in footballers with one or more restorations was 4.9 and 5.2 compared to 3.4 and 5.1 in the ADHS study. 
Clearly this comparison should be interpreted with caution as the examiners were not ADHS trained and the methodology for our examination will have been different (though based on the ADHS approach). Nevertheless, this is the first study on an adult elite sport population to attempt to relate oral health with population data and some of the differences are large.

\section{Strengths and limitations of data}

The strengths of the study are several. Dentists examined the vast majority of each senior squad $(89-100 \%)$ and the total sample size $(\mathrm{N}=189)$ is the largest in professional football and one of the largest single sport oral health surveys to be reported ${ }^{2}$. Therefore, it is reasonable to generalise the findings from this study to professional football, at least in the UK. We also employed validated oral health outcome measures that enable comparison across studies.

The main limitation of the study was that we used multiple examiners (six) for data collection. Examinations were carried out by team dentists who were recognised by each club and familiar with the medical organisation. We provided examiner training in the form of written materials and a teleconference. However there was no formal evaluation of examiner repeatability or calibration. In order to mitigate the effect of limited examiner training in research methods, we employed outcome measures familiar to the dental examiners and which represented obvious signs of disease. Furthermore, the dentists were highly experienced clinicians outside of research. Taking these aspects into account, estimates of disease levels in this study are most likely to under-report actual prevalence since no radiographs were taken.

\section{Implications for health and performance}

This study provides the most reliable evidence that oral health within professional football is poor and is consistent with research conducted in Brazil, Spain and the USA. The levels of caries, restorations, erosion and gingival inflammation are likely to confer a considerable burden in terms of existing and future treatment. The frequently reported oral symptoms and self-reported impacts on oral health quality of life and performance are also notable in view of the high level of football participation of these individuals. 
In accordance with Wilson \& Jungner screening criteria ${ }^{17}$, the screening of oral health seems fully justified within football given the high prevalence of treatable conditions. It is debatable whether many other routine screening tests performed in football meet all screening criteria.

Therefore, we recommend oral health screening within football. Oral health assessments may also provide indications on lifestyle habits (for example nutritional) beyond notoriously inaccurate self-report. Whilst appreciably subjective, many footballers within this study believed that their oral health had an impact on their quality of life and some on performance. Improved oral health will positively impact athlete quality of life, wellbeing and psychological preparedness for sport. The data also support oral health education of youth football players given the increase in oral disease with age.

The causes of poor oral health include nutrition ${ }^{18 ; 19}$, unfavourable individual health behaviours ${ }^{20}$, cultural norms and structural determinants such as access to oral health promotion and value of oral health within sport support system ${ }^{4}$. Notably, more than threequarters of participants reported attendance at a dentist for a check-up within 12 months and this is corroborated anecdotally by the participating dentists. However, few teams integrate oral health promotion within overall medical care and there is therefore lack of ongoing support and reinforcement of this health area for the athletes.

Interestingly there was significant variation in dental caries among clubs suggesting that differences in the prevention of oral disease may exist. The relationship between sports drinks and dental erosion remains unclear. A systematic review found no association although included only studies in children not specifically participating in sport ${ }^{19}$. In comparison, a European survey of more than 3000 participants aged 18-35 years reported a statistically significant association of sports drink use with dental erosion ${ }^{21}$. Pattern of use and titratable acidity may an important confounders ${ }^{21}$.

The principles of oral disease prevention and health promotion are well recognised and with good evidence of effectiveness ${ }^{22}$ including effective daily plaque removal, higher fluoride supplementation (toothpastes/mouthrinses) for high caries risk, and managing nutritional intake (including sports supplements) to reduce the frequency of fermentable carbohydrates (for caries) and acidic items (for dental erosion). Successful implementation 
will be dependent on integrating oral health within other areas of health promotion in sport and is likely to achieve mutual benefits ${ }^{4 ; 23 ; 24}$.

\section{Implications for research}

Studies are needed that investigate different models of oral health promotion within professional football. However, barriers to conducting research within the Football Association have been highlighted ${ }^{25}$. In view of the medical resource that are available, integration of oral health input within existing medical, nutritional and coaching support is likely to offer excellent potential to achieve change and with modest resource implications (cost, time or personnel). Such models should be based on best evidence for health behaviour change, health promotion ${ }^{26}$ and implementation science ${ }^{24}$. Further research should investigate oral health in youth football to identify earlier opportunities to embed oral health promotion.

\section{Summary}

The oral health of professional footballers is poor with self-reported impacts on wellbeing and performance. Despite attendance for dental check-ups, oral health deteriorates with age. Successful strategies to promote oral health within professional football are urgently needed and research should investigate models based on best evidence for behaviour change and implementation science. This study provides strong evidence to support oral health screening within professional football.

\section{Acknowledgements}

We would like to thank the players for taking part in this research. We are also hugely grateful to the football teams and especially the medical staff for their support to conduct this study including; Dr Helge Riepenhof (Brighton and Hove Albion FC), Dr Len Noakes (Cardiff City FC), Dr Steve Baynes (Southampton FC), Dr Jim Moxom (Sheffield United FC), Dr Kate Rees (Swansea City AFC) and Dr Mark Waller (Hull City Tigers). Our thanks also to Miss Sarah Needleman for data entry.

Competing interests 
None

Funding

The study was investigator led. Salaries of IN and PA were funded through UCL. A small grant was received from Manchester United FC to cover biostatistics analysis.

\section{Contributorship statement}

Ian Needleman planned the study and wrote the first draft of the publication and is overall responsible for the content as guarantor. Paul Ashley co-developed the study and worked on subsequent publication drafts. Dental examinations were conducted by Lyndon Meehan, Chris Ayer, Rob Hanna, lan Hunt, Steven Kell, Paul Ridgewell and Russell Taylor Aviva Petrie carried out the data analysis. Richard Weiler \& Steve McNally provided sport and exercise medicine expertise in the interpretation of the data and final manuscript. 
Reference List

(1) Needleman I, Ashley P, Petrie A, Fortune F, Turner W, Jones J et al. Oral health and impact on performance of athletes participating in the London 2012 Olympic Games: a crosssectional study. British Journal of Sports Medicine 2013; 47:1054-1058.

(2) Ashley P, Di lorio A, Cole E, Tanday A, Needleman I. Oral health of elite athletes and association with performance: a systematic review. British Journal of Sports Medicine 2015; 49:14-19.

(3) Needleman I, Ashley P, Meehan L, Loosemore M. Oral Health in Sport. A Position Statement. Faculty of Sport and Exercise Medicine 2014 Available from:

www.fsem.ac.uk/news/position-statements/o/oral-health-in-sport.aspx

(4) Needleman I, Ashley P, Fine P, Haddad F, Loosemore M, de Medici A et al. Oral health and elite sport performance. British Journal of Sports Medicine 2015; 49:3-6.

(5) Locker D. Measuring oral health: a conceptual framework. Community Dental Health 1988; 5:5-13.

(6) Foster Page LA, Thomson WM. Caries prevalence, severity, and 3-year increment, and their impact upon New Zealand adolescents' oral-health-related quality of life. Journal of Public Health Dentistry 2012; 72:287-294.

(7) Needleman I, McGrath C, Floyd P, Biddle A. Impact of oral health on the life quality of periodontal patients. J Clin Periodontol 2004; 31:454-457.

(8) McNutt M, Partrick M, Shugars DA, Phillips C, White RP, Jr. Impact of symptomatic pericoronitis on health-related quality of life. Journal of Oral \& Maxillofacial Surgery 2008; 66:2482-2487.

(9) Randell S. Dental trauma and disease in 34 professional athletes. 1983; 11:85-87.

(10) de Sant'Anna GR, Simionato MR, Suzuki ME. Sports dentistry: buccal and salivary profile of a female soccer team. 2004;16:649-652.

(11) Gay-Escoda C, Vieira-Duarte-Pereira DM, Ardevol J, Pruna R, Fernandez J, ValmasedaCastellon E. Study of the effect of oral health on physical condition of professional soccer players of the Football Club Barcelona. 2011; 17:e436-e439.

(12) Locker D, Quinonez C. To what extent do oral disorders compromise the quality of life? Community Dentistry and Oral Epidemiology 2011; 39:3-11.

(13) Bartlett D, Ganss C, Lussi A. Basic Erosive Wear Examination (BEWE): a new scoring system for scientific and clinical needs. Clin Oral Invest 2008; 12:65-68.

(14) British Society of Periodontology. Basic Periodontal Examination. BSP 2011 Available from: www.bsperio.org.uk 
(15) Monse B, Heinrich-Weltzien R, Benzian H, Holmgren C, Van Palenstein Helderman W. PUFA An index of clinical consequences of untreated dental caries. Community Dentistry and Oral Epidemiology 2010; 38:77-82.

(16) Steele J, O'Sullivan I. Executive Summary: Adult Dental health Survey 2009. Health and Social Care Information Centre [2009 Available from:

www.hscic.gov.uk/catalogue/PUB01086/adul-dent-heal-surv-summ-them-exec-2009rep2.pdf

(17) Wilson JMG, Jungner G. Principles and Practice of Screening for Disease. WHO [1968 Available from: http://apps.who.int/iris/bitstream/10665/37650/1/WHO_PHP_34.pdf?ua=1

(18) Moynihan PJ, Kelly SA. Effect on caries of restricting sugars intake: systematic review to inform WHO guidelines. J Dent Res 2014; 93:8-18.

(19) Li H, Zou Y, Ding G. Dietary Factors Associated with Dental Erosion: A Meta-Analysis. PLoS ONE 2012; 7:e42626.

(20) Watt RG. From victim blaming to upstream action: tackling the social determinants of oral health inequalities. Community Dentistry \& Oral Epidemiology 2007; 35:1-11.

(21) Bartlett DW, Lussi A, West NX, Bouchard P, Sanz M, Bourgeois D. Prevalence of tooth wear on buccal and lingual surfaces and possible risk factors in young European adults. Journal of Dentistry 41:1007-1013.

(22) Public Health England. Delivering better oral health: an evidence-based toolkit for prevention. 3rd Edition. PHE 2014 Available from:

www.gov.uk/government/uploads/system/uploads/attachment_data/file/367563/DBOHv32 0140CTMainDocument_3.pdf

(23) Dijkstra HP, Pollock N, Chakraverty R, Alonso JM. Managing the health of the elite athlete: a new integrated performance health management and coaching model. British Journal of Sports Medicine 2014; 48:523-531.

(24) Verhagen E, Voogt N, Bruinsma A, Finch CF. A knowledge transfer scheme to bridge the gap between science and practice: an integration of existing research frameworks into a tool for practice. British Journal of Sports Medicine 2014; 48:698-701.

(25) Stone M. Football Medicine in England: A peronal perspective on protocols, standards, and moving the field forward. BJSM online 2014 Available from:

http://blogs.bmj.com/bjsm/2014/09/13/football-medicine-in-england-a-personalperspective-on-protocols-standards-and-moving-the-field-forward/

(26) Engebretsen L, Bahr R, Cook JL, Derman W, Emery CA, Finch CF, Meeuwisse WH, Schwellnus M, Steffen K. The IOC Centres of Excellence bring prevention to sports medicine._Br J Sports Med. 2014;48:1270-1275. 